\title{
Fault zone conductors in Northwest Turkey inferred from audio frequency magnetotellurics
}

\author{
S. Bülent Tank ${ }^{1,2}$ \\ ${ }^{1}$ Tokyo Institute of Technology, Volcanic Fluid Research Center, Tokyo, Japan \\ ${ }^{2}$ Department of Geophysics, Kandilli Observatory and E.R.I., Boğaziçi University, İstanbul, Turkey
}

(Received August 17, 2010; Revised January 23, 2012; Accepted February 14, 2012; Online published September 18, 2012)

\begin{abstract}
A comparison of the electrical properties of the two main branches of the North Anatolian Fault is made based on audio-frequency magnetotelluric (AMT) surveys carried out along three typical pro les across the North Anatolian Fault Zone (NAFZ). These two branches are (i) the active northern branch (Izmit-Adapazar Fault (IAF)) where the 17 August, 1999, Izmit earthquake took place, and (ii) the less active southern branch (IznikMekece Fault (IMF)). In this paper, we focus on the shallow depths (surface-1.5 km) in search for conductors near the fault zone for the purpose of comparing these two branches with each other, as well as other strike-slip faults. Phase tensor analyses and Groom-Bailey decompositions were applied to check the dimensionality of the AMT data. Following the tensor analyses and decompositions, two-dimensional inversions were carried out to yield models based on the transverse electric (TE), and transverse magnetic (TM), modes. These models suggest that the North Anatolian Fault exhibits signs of fault zone conductors (FZC) regardless of being active or less active.
\end{abstract}

Key words: Audio frequency magnetotellurics, electrical resistivity, uids, fault zone conductors, North Anatolian Fault.

\section{Introduction}

The North Anatolian Fault Zone (NAFZ) was formed approximately between the Late Miocene and early Pliocene, according to Barka (1992), or around 13 Ma according to Şengör et al. (2005). It starts near Karl ova as a single strand in eastern Turkey and continues to the west where it divides into several strands (Barka, 1992) near the Marmara Sea before it enters the Aegean Sea (with its age estimated to be $200 \mathrm{ka}$ (Şengör et al., 2005)). The North Anatolian Fault is a dextral strike-slip fault and has almost constantly generated large earthquakes in an east-west aligned 1200km-long zone (Parsons et al., 2000; Şengör et al., 2005). Although the North Anatolian Fault shows mechanical similarities with other major strike-slip faults, such as the San Andreas Fault (SAF) in California, its westward migrating and cyclic seismic behavior traced back to the 17 th century (Şengör et al., 2005), gives it a unique character and provides an ideal laboratory for geoscientists studying earthquakes and their generation mechanisms. Fault zones are typically characterized by two distinct structural and hydrogeological units, which play important roles in the architecture of the fault and uid ow. These units are fault core and its damage zone (Caine et al., 1996; Gundmundsson, 2000). Fault cores, where most of the fault displacement is localized, may be less than tens of centimeters thick compared to damage zones which typically have widths of ap-

Copyright (C) The Society of Geomagnetism and Earth, Planetary and Space Sciences (SGEPSS); The Seismological Society of Japan; The Volcanological Society of Japan; The Geodetic Society of Japan; The Japanese Society for Planetary Sciences; TERRAPUB.

doi:10.5047/eps.2012.02.001 proximately one kilometer (Eberhart-Phillips et al., 1995). The damage zones build up due to the mechanical development of the associated core and they comprise minor faults, fractures, fracture networks and subsidiary structures, all related to the main fault growth processes.

Several studies point out that active fault zones receive and transport great amounts of uid (Hickman et al., 1995; Gundmundsson, 2000). These zones can act as conduits, barriers or as conduit-barrier systems (Caine et al., 1996). The uid can nd paths through the highly permeable rocks, which depend on the uid-triggered deformation (acting as a complex feedback mechanism (McCaig et al., 1988)). Secondly, they may act as barriers for uid ow due to lithological differences that are caused by the displacement of the fault's blocks. One resulting possibility is that the fault zone may act as a combination of these two options, which can be named as a conduit-barrier system fault (Caine et al., 1996; Ritter et al., 2005).

The urge to monitor the uid around the fault zones has stimulated the development of various techniques in the eld of geophysics. There are several different methods to remotely detect the presence of uid within the crust (Eberhart-Phillips et al., 1995). Since the electrical properties of crustal material heavily depend on the uid content, techniques that are sensitive to variations in electrical properties offer plausible solutions to the problem. Among several electromagnetic techniques, magnetotellurics (MT) can be considered as one of the promising methods for imaging uids in the crust and upper mantle (Ogawa et al., 2001, 2002).

MT studies aimed at investigating the relationship be- 


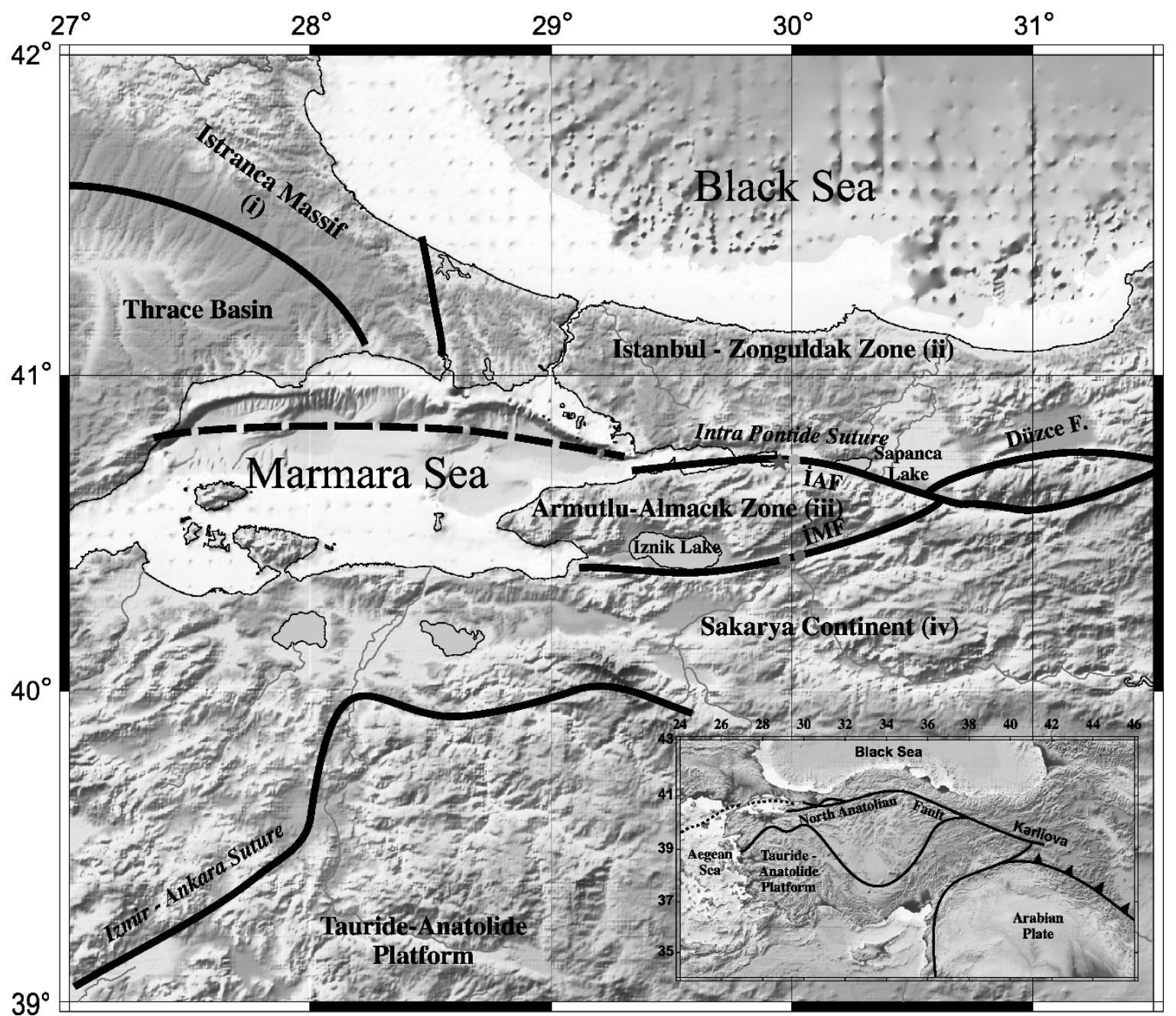

Fig. 1. Map showing the geological features around the study area. The red star represents the 1999 Izmit Earthquake's epicenter. Yellow, orange and blue dots represent the approximate locations of the AMT-A, AMT-B and AMT-C pro les, respectively. The small-scale map shows the major tectonic elements in the study area, such as the Anatolian plate, Arabian plate and North Anatolian Fault.

tween the fault and the electrical resistivity structure have been carried out in many major fault regions around the world. Some important instances of these studies are as follows. Hoffmann-Rothe et al. (2004) investigated the West Fault (WF) in northern Chile. Ritter et al. (2003) studied the Avara Fault (AvF) on the Dead Sea Transform in Jordan where they found an impermeable barrier for uid ow. Bedrosian et al. $(2002,2004)$ surveyed and imaged the San Andreas Fault (SAF) near a creeping segment at Hollister. They pointed out a vertical conductor at the fault zone extending to a depth of 6-7 km and related this conductor with extensive creeping. A detailed study on the Alpine Fault (AIP) in New Zealand by Wannamaker et al. (2002) claimed that the uid in the interconnected pores plays an active role in the formation of a brittle-ductile transition zone. Ogawa et al. (2001) discussed the magnetotelluric imaging of $\mathrm{u}$ ids in the intraplate earthquake zones of the northeastern Japan back-arc region. They found correlations between the seismic scatterers, seismic low-velocity zones and electrical conductors. Mitsuhata et al. (2001) studied the seismogenic region of the 1962 M 6.5 northern Miyagi earthquake in northeastern Japan. Similar to Ogawa et al. (2001), they pointed out that seismicity took place in an electrically- resistive zone, underlain by a conductor. Unsworth et al. (1997, 1999) examined the Carrizo Plain and the Park eld area where the SAF exhibits very different patterns of seismicity. Unsworth et al. (1997) compared seismic re ection images with MT results for the SAF and gave geological interpretations for the Park eld area, California. Mackie et al. (1997) investigated the SAF at the Carrizo Plain, California. It should be noted here that fault-related MT studies started in the 1980's by the Electromagnetic Research Group for the Active Fault (1982); in fact it showed high conductivity anomalies associated with active faults.

Ritter et al. (2005) reviewed some of the large fault systems mentioned above (namely AvF, WF and SAF), compared their electrical properties, and proposed some Earth models that attempted to decipher the electrical information in a geological sense.

In this paper, we present new high-resolution AMT survey results with the intention of elucidating the shallow (surface-1.5 km) electrical conductivity structure at the western part of the NAFZ, including the Izmit-Adapazar Fault (IAF) near the 17 August, 1999, Izmit earthquake epicentral zone and the seismic gap on the Iznik-Mekece Fault (IMF). First, the study area and the MT data collec- 


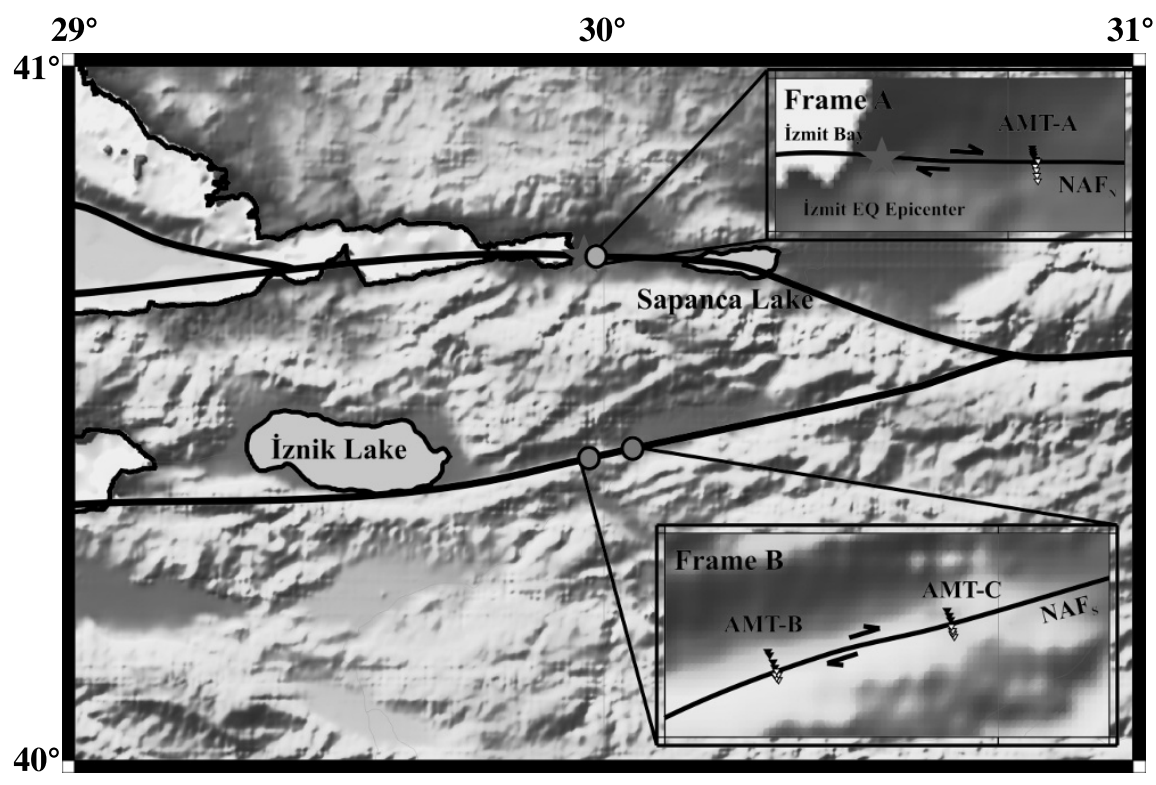

Fig. 2. Map showing the AMT-A, AMT-B and AMT-C profiles.

tion will be described. Next, dimensionality determination of the data is introduced and, finally, the results of twodimensional modeling and their interpretations are given.

\section{Tectonic Setting of the Study Area}

The evolution of the Marmara region in northwestern Anatolia has a complex history. The area is formed by tectonic amalgamation of four different regions. These are (i) the Istranca Massif, (ii) the İstanbul-Zonguldak Zone, (iii) the Armutlu-Almackk Zone and (iv) the Sakarya Continent. These tectonic zones are separated from each other by some structural elements of transform faults or suture zones as shown in Fig. 1 (Yılmaz et al., 1995; Yiğitbaş et al., 1999). As the NAFZ enters northwestern Turkey, it widens in a rather north-south alignment and splays into several branches (Barka, 1996). These branches are acting as geological boundaries that separate the four entities (Y1lmaz et al., 1995). The northernmost branch is seismically active and known to act as a tectonic boundary between the İstanbul-Zonguldak Zone and the Armutlu-Almacık Zone which also coincides with the Intra-Pontide Suture. This branch of the NAFZ experienced a 7.4 magnitude earthquake on 17 August 1999. Another branch appears about 20 to $40 \mathrm{~km}$ south of the northernmost branch as shown in Fig. 2 and has been supposed to be a seismic gap (Toksöz et al., 1979).

\section{Audio Frequency Magnetotellurics (AMT) Data Collection}

The first MT sounding was performed in the vicinity of İzmit in the early 90's (Gürer, 1996), whereas modern highresolution wide-band MT data with denser sounding sites were collected near the 1999 İzmit earthquake epicenter. Honkura et al . (2000) and Oshiman et al. (2002) made similar MT surveys and showed the preliminary results as twodimensional Earth models. Tank et al. (2003) then imaged the western part of the epicentral region of the Izmit earthquake, in order to study the electrical resistivity structure with respect to the characteristic seismic behavior. Tank et al. (2005) added long-period data to the wide-band dataset of Honkura et al. (2000) and proposed a deep (surface-50 $\mathrm{km}$ ) electrical-conductivity model for the eastern Marmara region. Kaya et al. (2009) performed a comparison between the eastern and western parts of the Düzce Fault (Fig. 1), where the Düzce earthquake occurred in 1999, by using their wide-band MT data, and tried to relate the resistivity structure with the asperity zones in the study area.

In our present study, four-channel (Ex, Ey, Hx, Hy) AMT soundings were performed at 28 sites along three typical profiles at the western part of the NAFZ (Frames A and $B$ in Fig. 2). Profile AMT-A crossed the active IAF and Profiles AMT-B and AMT-C crossed the IMF of the NAFZ which is supposed to be a seismic gap (Toksöz et al., 1979). The soundings were made using two Phoenix Geophysics systems (MTU5A) with the appropriate magnetic coils (AMTC-30). $\mathrm{Pb}-\mathrm{PbCl}_{2}$ electrodes were used for measuring the electric field.

A modern audio-frequency MT system covers 5 orders of magnitude in frequency $(10 \mathrm{kHz}-0.1 \mathrm{~Hz})$ and this range is sensitive to shallow depths down to $1-2 \mathrm{~km}$, depending on the conductivity structure beneath the sounding locations. The natural sources in this frequency range are mainly due to lightning discharges. The remote-reference processing technique (Gamble et al., 1979) has usually been used in MT and AMT surveys to avoid contamination due to noise. In fact, we applied this technique in this study in order to reduce noise contamination at some of the sites.

\section{1 İzmit-Adapazarı Fault (IAF)}

The İmit-Adapazarı Fault of the NAFZ cuts through a Plio-Pleistocene basin, which accommodates Sapanca Lake (Ikeda, 1988) (Fig. 1). This basin is filled mostly with sandstones and conglomerates, appearing as lacustral coarse clastic rocks. There are indications that marls exist in this area (Şengör et al., 2005). On both sides of the fault, marls and sandstones are detected. Inbetween these rocks there stands a 40- to 100-m-thick alluvium layer (Şengör et al., 
2005). IAF is an active branch of the NAFZ, which accommodated 17 August, 1999, magnitude 7.4 Izmit earthquake. The AMT-A pro le lies approximately $5 \mathrm{~km}$ east of the 1999 earthquake's epicenter (Fig. 2, Frame A). The fault trace at this location was determined visually following the earthquake occurrence and the pro le was selected accordingly. Five of the AMT sites were positioned to the north of the trace (black reverse triangles) and ve others to the south of the trace (white reverse triangles) (Figs. 2 and $6(\mathrm{~A}))$. The site separations were chosen to be as dense as possible, ranging from $50 \mathrm{~m}$ to $150 \mathrm{~m}$, resulting in a long pro le crossing the northern branch of the North Anatolian Fault in the region.

\section{2 İznik-Mekece Fault (IMF)}

The IMF of the NAFZ stands as a geological boundary between the Sakarya Continent in the south and the Armutlu-Almac k Zone in the north. Toksöz et al. (1979) regarded the area as a seismic gap. A displacement of about $25 \mathrm{~km}$ was found for Tertiary rocks along this branch of the NAFZ (Sipahioglu and Matsuda, 1986). To the north of the fault trace there are Pre-Permian marbles and metamorphic rocks. These rocks are covered with alluvium, especially near the southeastern coast of Iznik Lake. To the south of the fault trace, some Eocene-aged crashed andesites are present. Below these andesites there are Upper Cretaceous Limestone and Lower Eocene Turbidites (Bargu, 1982).

The AMT-B and AMT-C pro les crossed the IMF in a manner similar to AMT-A crossing the IAF, but here the exact location of the fault was inferred from geological and geomorphological investigations (Sipahioglu and Matsuda, 1986) and also from magnetic anomaly observations (Tunçer et al., 1991). The AMT-B pro le consisted of 10 AMT sites with 5 of them on both sides of the fault trace (Figs. 2 and 6(B)). The pro le crosses the metamorphic rocks, crashed andesites and limestone from north to south. The AMT-C pro le, on the other hand, had 8 sites in a structurally more complicated area, crossing crashed andesites and sandstones.

\section{Dimensionality}

One of the major problems in magnetotellurics data is the contamination caused by near-surface three-dimensional (3D) structures (frequency independent) in the twodimensional (2D) regional structure (frequency dependent). This effect is commonly referred to as 'galvanic distortion' and is generally faced in real Earth problems, where the effect may be strong enough to mask the target structure of the MT survey. These distortions are typically observed (especially in land surveys) in the electric eld rather than the horizontal magnetic eld. The charge accumulation at the near-surface heterogeneity boundaries, either because of a conductivity anomaly or because of a radical change in topography, is supposed to be the mechanism. The primary goal of dimensionality analysis is to investigate the intensity of the distortion effects caused by the near-surface heterogeneities and eliminate their in uence on the measured MT impedance tensor.

There have been several methods and decomposition techniques so far proposed to examine contaminated data and remove the surplus effects: they are Groom and Bai- ley (GB) decomposition (Groom and Bailey, 1989), Smith's method (Smith, 1995), Bahr's parameters (Bahr, 1988, 1991), multi-site-multi-frequency approach to GB decomposition (McNeice and Jones, 2001), and phase tensor (PT) analysis (Caldwell et al., 2004; Bibby et al., 2005).

In this paper, we have used the PT analysis and the GB decomposition.

\subsection{Phase tensor analysis}

In complex environments where the structure is multidimensional (2D or 3D), the phase relationship extracted from the impedance tensor contains valuable information, which can be used in identifying some crucial electrical properties of the data (Caldwell et al., 2004). Under such circumstances, the phase relationship of the electromagnetic eld might be more useful than the amplitude of the measured electric eld. This is mainly because in such environments the galvanic distortions caused by the near-surface heterogeneities severely in uence the amplitude of the measured electric eld, whereas the phase relationship of the electromagnetic eld stays unaffected (Caldwell et al., 2004).

The graphical representation of phase tensors as ellipses includes the parameters $\Phi_{\min }, \Phi_{\max }, \alpha$ and $\beta . \Phi_{\min }$ and $\Phi_{\max }$ are de ned as the semi-minor and semi-major axes of the ellipse, whereas $\alpha$ de nes the position of a reference axis to the coordinate axis and $\beta$ de nes the position of the principlal axis of the ellipse relative to the reference axis (Caldwell et al., 2004; Bibby et al., 2005; Heise et al., 2006).

Figures 3(A), (B) and (C) present phase tensor ellipses at every four frequencies for the AMT-A, AMT-B and AMT$\mathrm{C}$ pro les, respectively. These gures show the differences in dimensionality and the geo-electric strike directions of the data for all three pro les. The phase tensor ellipses are normalized to the maximum phase value and changes in the direction of their major axes are examined for checking the geo-electrical strike direction. By making a comparison between ellipses for the AMT-A, AMT-B and AMT-C pro les, it is pointed out that AMT-A and AMT-C data show a more complicated picture than the AMT-B data. Painting the $\beta$ value is another way to observe the dimensionality changes at a particular frequency. The color scales in Figs. 3(A), (B) and (C) illustrate the values of $\beta$ for the AMT-A, AMT$\mathrm{B}$ and AMT-C pro les, respectively. The complicated data at the AMT-A pro le can also be inferred from an examination of the $\beta$ values (Fig. 3(A)). Since the $\beta$ values represent the asymmetrical part of the tensor and their departure from 0 corresponds to a variation from two-dimensionality, large values of $\beta$ (red or dark blue) observed in the AMT-A prole indicate that $3 \mathrm{D}$ effects are rather strong in the data of this pro le. Similarly, low $\beta$ values (light green) viewed in the AMT-B pro le are signs of 2D data (Fig. 3(B)). Low $\beta$ values appear on the northern part of the AMT-C pro le. The southern part of this pro le seems to have more complicated data.

\subsection{Groom and Bailey decomposition}

The inverse technique proposed by Groom and Bailey (1989) has been widely used (McNeice and Jones, 2001). The technique removes the distortion effects and calculates a geo-electric strike direction for data.

The GB decompositions for our data set were performed 


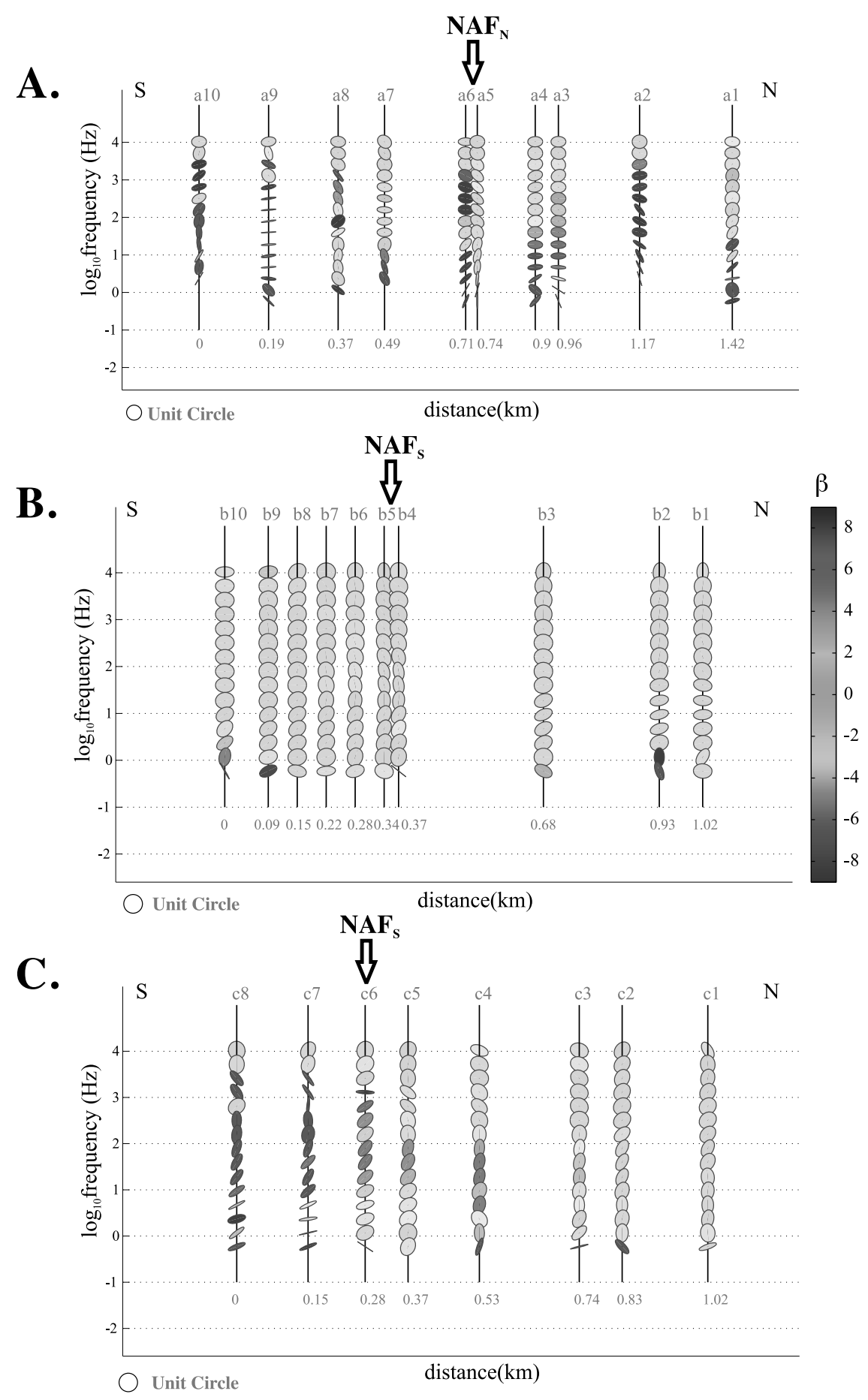

Fig. 3. Phase tensor ellipses at every 4th frequency for the (A) AMT-A, (B) AMT-B and (C) AMT-C profiles together with $\beta$ values.

by means of two different approaches. The first approach handles each observation site separately (so-called site-bysite), while the second approach handles the sites all together (so-called multisite) as one single profile (McNeice and Jones, 2001). The site-by-site analysis was performed in two different ways as well. The first way was such that all frequencies were put into the code separately, which eventually calculated several different strike angle values for different frequencies, following the tensor decomposition. In the second way, all frequencies were combined to calculate a single strike for each site. A similar style was followed in the calculation using the multisite approach.
Figure 4(A) presents root-mean-square values at some sample sites for GB decompositions performed site-by-site, frequency by frequency for AMT-A (1st row), AMT-B (2nd row) and AMT-C (3rd row) profiles. The ordinate of these graphs gives the frequencies and the abscissa gives the strike angle values in the first quadrant at 3-degree intervals (0-90). Red (blue) colors represent good (poor) fitting. There is a clear difference between the profiles regarding the distribution of the root-mean-square values. The AMTA and AMT-C profiles obviously represent poor fitting values at certain frequency intervals, while the AMT-B profile represents a significantly clearer fit. By examining these 


\section{GB decomposition results}

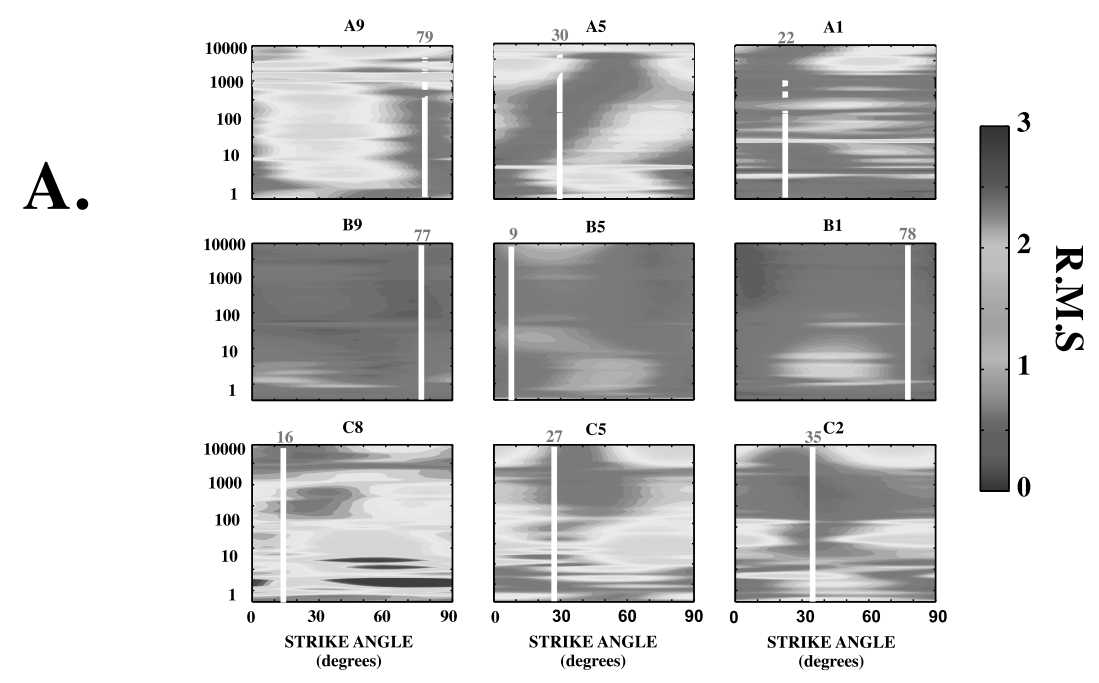

B.

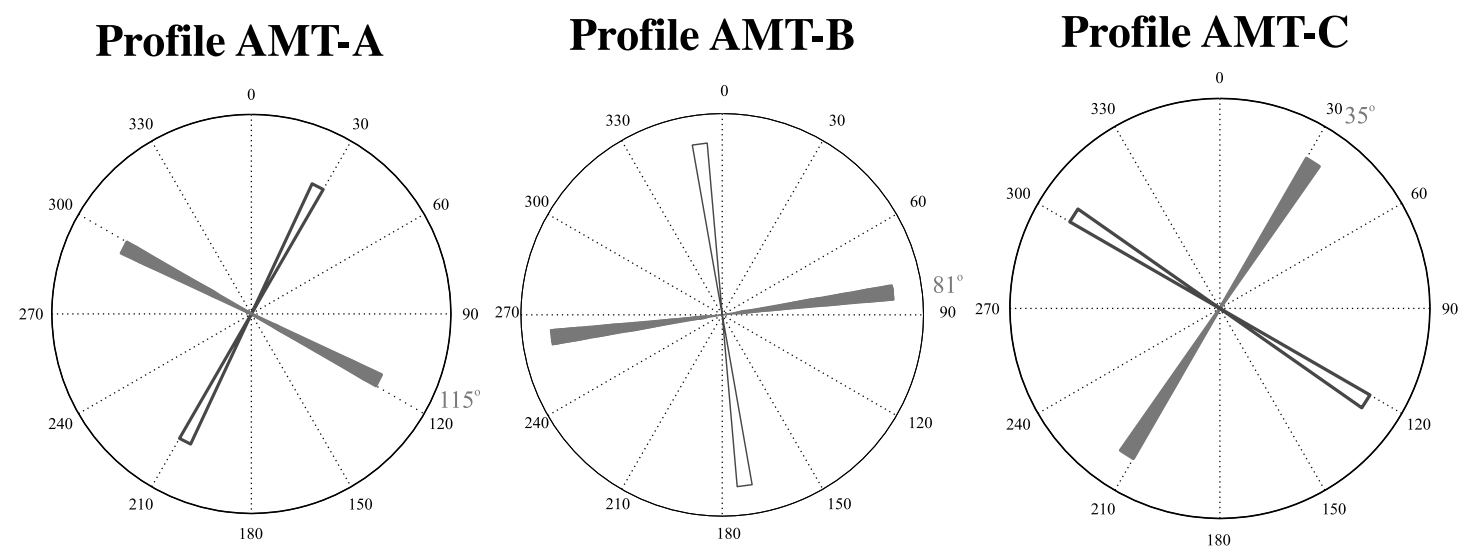

$10000-0.1 \mathrm{~Hz}$

Fig. 4. (A) Root-mean-square values for geo-electric strike directions at every 3 degree intervals in the first quadrant (between 0-90) after Groom and Bailey decomposition performed at sample observation sites. White bars (and the values above them) on each graph represent the geo-electric strike direction calculated by site-by-site GB decomposition. (B) Rose diagrams for the AMT-A, AMT-B and AMT-C profiles after multi-site-multi-frequency GB decomposition.

graphs in Fig. 4(A), it would not be difficult to claim that both the AMT-A and AMT-C profiles show more signs of multi-dimensionality as compared to the AMT-B profile.

The white vertical lines in each graph give the strike angles calculated after GB decomposition for all available frequencies at the respective sites to give a single strike angle (site-by-site-multi-frequency) for respective sample sites. The resulting strike angles belonging to each sample site are shown in red on the top of each vertical line. It is clear from the figures that the white vertical lines representing the strike angle values coincide well with red (good fitting) areas.
The rose diagrams in Fig. 4(B) show the multi-site-multifrequency approach results for the three AMT profiles. Because of the ambiguity in the calculation of the strike angle, they indicate two likely angles as geo-electric strikes. Considering some structural features in both profiles, such as the fault alignment, N115E, N81E and N35E are chosen as the strike angles for the AMT-A, AMT-B and AMT$\mathrm{C}$ profiles, respectively. These angles are printed in red in Fig. 4(B). 


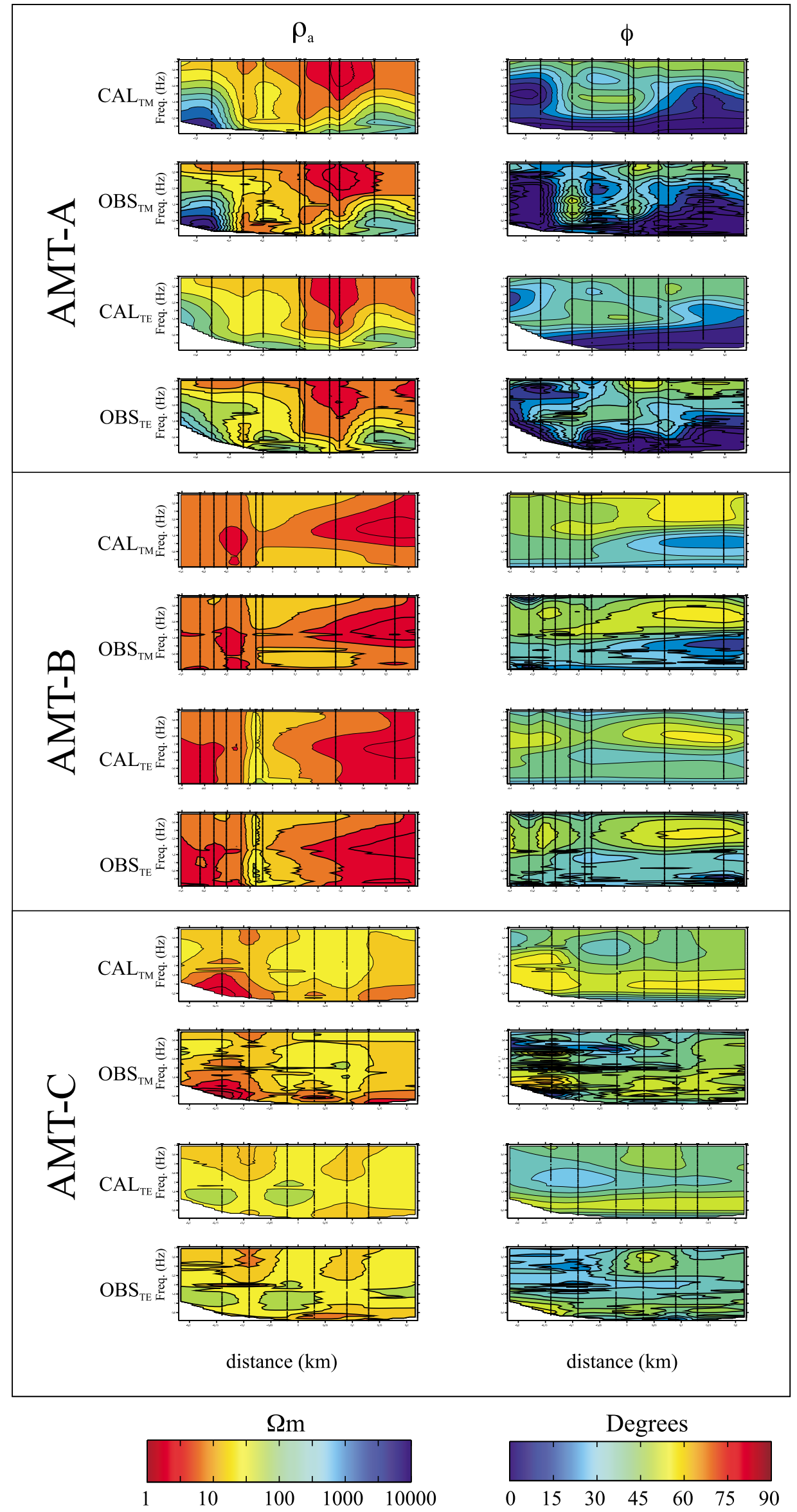

Fig. 5. Observed and calculated pseudo-sections of apparent resistivity and phase for TM and TE modes at the AMT-A, AMT-B and AMT-C profiles. 


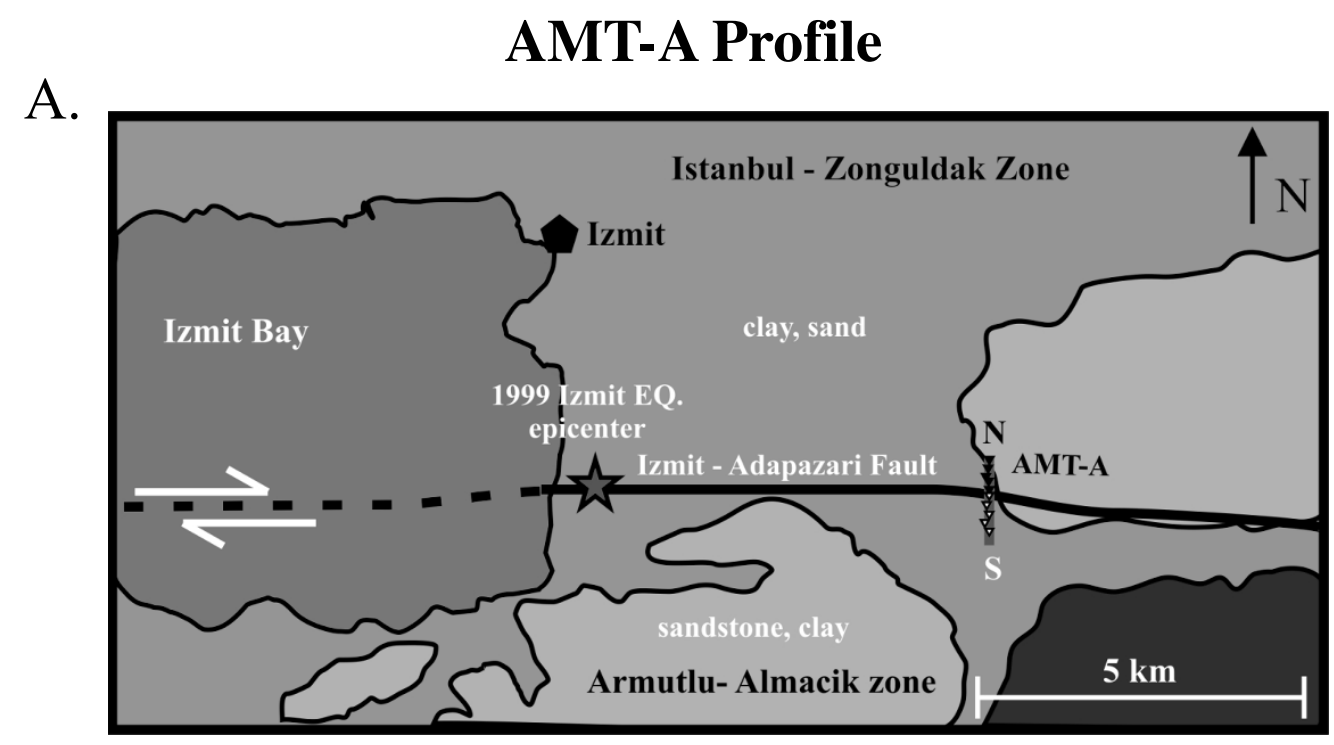

AMT-B and AMT-C Profiles

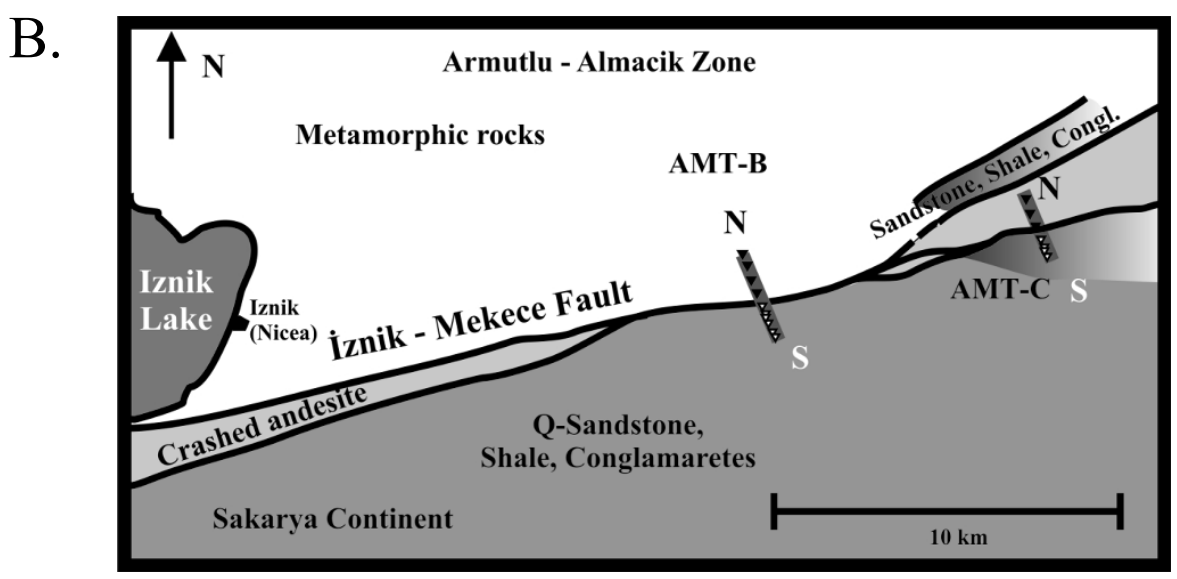

Fig. 6. (A) Schematic map showing the geological features and the site locations of the AMT-A profile and (B) the AMT-B and AMT-C profiles, respectively.

4.3 Comparison between Groom and Bailey decomposition results and phase tensor analysis results

The geo-electrical strike directions for the three AMT profiles computed following the GB decompositions agree well with the phase tensor orientations observed especially at low frequencies (Figs. 3 and 4). This feature can be most clearly seen on the AMT-B profile, where the phase tensor ellipses point out less complicated data compared to the other two profiles. On this profile, phase tensor ellipses are more consistent with each other at different observation points and at varying frequencies. Likewise, most of the $\beta$ values are low. Although the geo-electrical strike directions, calculated as a result of a site-by-site analysis of GB decomposition, do not often suggest a wide range on some AMT-B sites (Fig. 4(A)), the multi-site-multi-frequency approach yielded a similar value as suggested by the phase tensor ellipses. Inconsistencies between the phase tensor ellipse orientations and the geo-electrical strike direction, calculated following GB decompositions, are observed when $\beta$ reaches high values. This can be clearly seen on the AMT-A and AMT-C data.

\section{Two-Dimensional (2D) Inverse Modeling}

Two-dimensional modeling was performed by using a code developed by Ogawa and Uchida (OU) (1996). OU uses a finite element method solver, and its inversion scheme depends on ABIC (Akaike's Bayesian Information Criterion), a statistical approach which includes the entropy-maximization theorem in Bayesian statistics (Uchida, 1993). The aim of the code is to seek minimization of data misfit, model roughness $\left(\alpha_{1}\right.$ and $\left.\alpha_{2}\right)$ and the static shift parameter $(\beta)$, simultaneously $\left(\alpha_{1}, \alpha_{2}\right.$ and $\beta$ here should not be confused with the phase tensor parameters presented earlier). The static shift parameter in OU is assumed to have a Gaussian distribution as it appears in the 2D Occam approach of de Groot-Hedlin and Constable (1990) with a minor difference. OU does not require having a zero sum for the static shift parameter (Ogawa and Uchida, 1996).

During the inversions, a mesh size of $65 \times 85$ was used. Tensor decomposed data were fed into the inversion code with a $10 \%$ error floor for the apparent resistivity and $2.86^{\circ}$ for the phase. The code run 15 times iteratively and in all 

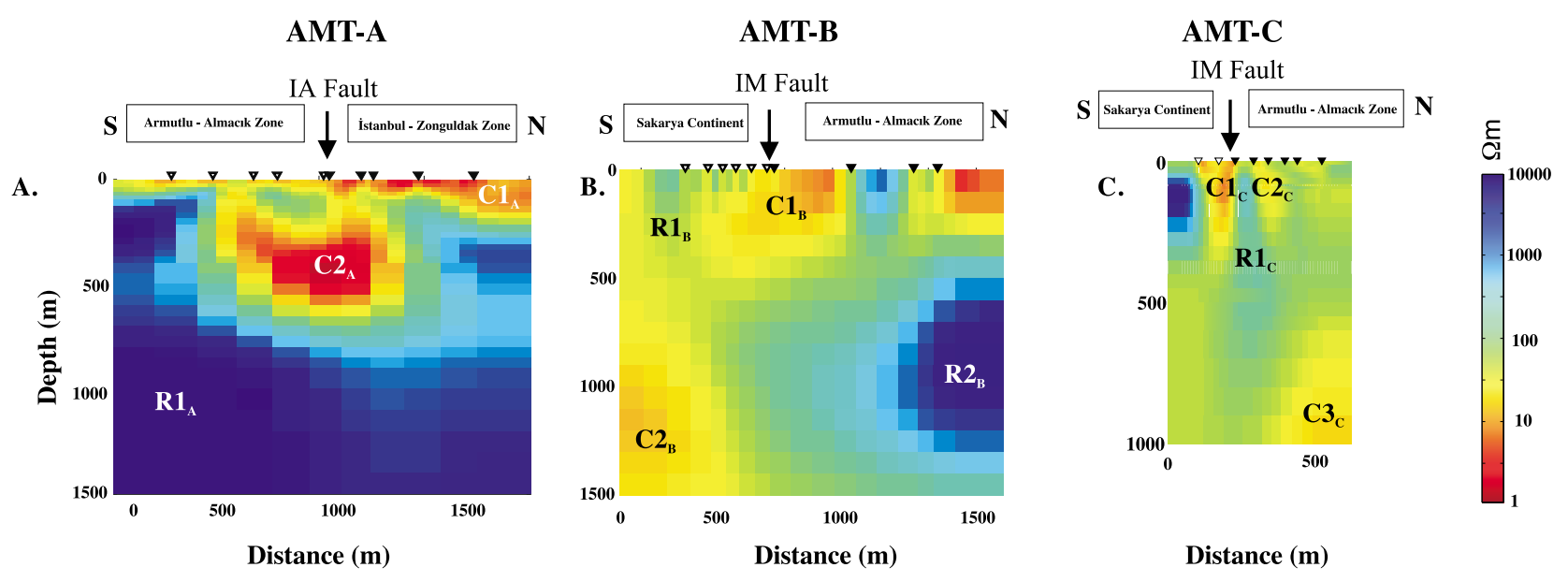

Fig. 7. (A) Final resistivity model for the AMT-A profile. Reverse triangles (white for south sites, black for north sites) represent the site locations. The arrow indicates the exact location of İzmit-Adapazarı Fault. (B) Final resistivity model for the AMT-B profile. Reverse triangles (white for south sites, black for north sites) represent the site locations. The arrow indicates the exact location of the Iznik-Mekece Fault. (C) Final resistivity model for the AMT-C profile. Reverse triangles (white for south sites, black for north sites) represent the site locations. The arrow indicates the exact location of the İznik-Mekece Fault.

iterations it created five candidate models to choose the best one for the next iteration. The overall root-mean-square misfit calculated for TE and TM mode final models for the AMT-A, AMT-B and AMT-C profiles were 2.74, 1.84 and 2.72 , respectively.

In two-dimensional analysis, on some occasions the TM only mode can give efficient results in resolving lateral conductivity variations and can provide robust images when the structure is mostly three-dimensional (Ting and Hohmann, 1981). To check this we performed TM only mode inversions. However, no clear difference between the inversion results of TE and TM mode inversions and TM only mode inversions were detected. For this reason our interpretations are based on TE and TM mode results.

Figure 5 shows the observed and calculated apparent resistivity and phase pseudo-sections for the AMT-A, AMT$\mathrm{B}$ and AMT-C profiles after TE and TM mode inversions. This figure demonstrates that the fitting between the observed data and model responses are reasonable.

\subsection{D modeling for İzmit-Adapazarı Fault (IAF)}

Figure 7(A) shows the final 2D electrical resistivity structure of the AMT-A profile crossing the IAF derived from joint inversion for the TE and TM modes. It is seen that the surface is covered with a conductive layer $\left(\mathrm{C}_{\mathrm{A}}: 1-10\right.$ $\Omega \mathrm{m}, \sim 100 \mathrm{~m}$ thickness $)$. Near the fault trace $\mathrm{C} 1_{\mathrm{A}}$ becomes thinner $(\sim 20 \mathrm{~m})$ and it becomes thicker towards the north reaching a depth of $250-300 \mathrm{~m}$. Beneath $\mathrm{Cl}_{\mathrm{A}}$, a resistive layer $\mathrm{R} 1_{\mathrm{A}}$ is present on both sides of the fault's trace.

The principal feature of the model in Fig. 7(A) is a Ushaped conductor $\left(\mathrm{C} 2_{\mathrm{A}}\right)$ with two sharp inlets. The width of $\mathrm{C} 2 \mathrm{~A}$ is about $700-800 \mathrm{~m}$ and it reaches a depth of almost $750 \mathrm{~m}$.

\subsection{D modeling for İznik-Mekece Fault (IMF)}

Figure 7(B) presents the 2D electrical resistivity structure of the IMF at the AMT-B profile derived from TE and TM mode inversions. The conductive region $\left(\mathrm{Cl}_{\mathrm{B}}\right)$ (Fig. $7(\mathrm{~B})$ ) may be representing a conductor zone at the vicinity of the fault trace. At a depth of $500 \mathrm{~m}$ below the fault trace, there appears a sharp boundary between the sandstone formations of the Sakarya Continent and the metamorphics of the transition zone. They are presented as $\mathrm{C} 2{ }_{\mathrm{B}}$ and $\mathrm{R} 2 \mathrm{~B}_{\mathrm{B}}$.

Figure 7(C) shows the final two-dimensional electrical resistivity structure of the AMT-C profile on the IMF further to the east. There are two shallow conductors at this profile, which are denoted as $\mathrm{C}_{\mathrm{C}}$ and $\mathrm{C} 2_{\mathrm{C}}(\mathrm{Fig} .7(\mathrm{C}))$ located near the fault location. $\mathrm{C} 1_{C}$ might represent a fault zone conductor at this profile, and crashed andesites are also clear at this location as denoted by $\mathrm{R} 1_{\mathrm{C}}$. The size of the conductive zone below the fault trace for the AMT-C profile is smaller compared to the one for the AMT-B profile. Furthermore, there is a deep conductive block in the northern half of the profile $\left(\mathrm{C} 3_{\mathrm{C}}\right)$, which might represent the sandstone formations at this location.

\section{Discussion}

Near-surface vertical conductors have been imaged at several strike-slip faults. Studies of the San Andreas Fault near Parkfield, Carrizo Plain (Unsworth et al., 1997, 1999) and Hollister (Bedrosian et al., 2002, 2004) showed apparent fault zone conductors (FZC) with varying electrical properties. These studies claimed that the FZC developed due to the saline fluids within the fractured rocks forming the fault gouge and breccia. Becken et al. (2008) imaged the deep resistivity structure (surface-25 km) near the San Andreas Fault Observatory at Depth (SAFOD) and also pointed out the presence of FZC. MT images for the West Fault in northern Chile confirmed earlier studies and showed FZCs (Hoffmann-Rothe et al., 2004).

Based on some laboratory measurements for the Parkfield area, Park and Roberts (2003) opposed the interpretation that the FZC is due to saline fluids in fractured rocks. They pointed out that the conductivity increased because of sedimentary formations in the Franciscan Syncline. They also pointed out that Mackie et al. (1997) failed to image an FZC for the SAF. Similarly, Ritter et al. (2003) failed to image an FZC for the Avara Fault on the Dead Sea Transform Fault.

At both the northern branch (IAF) and the southern 

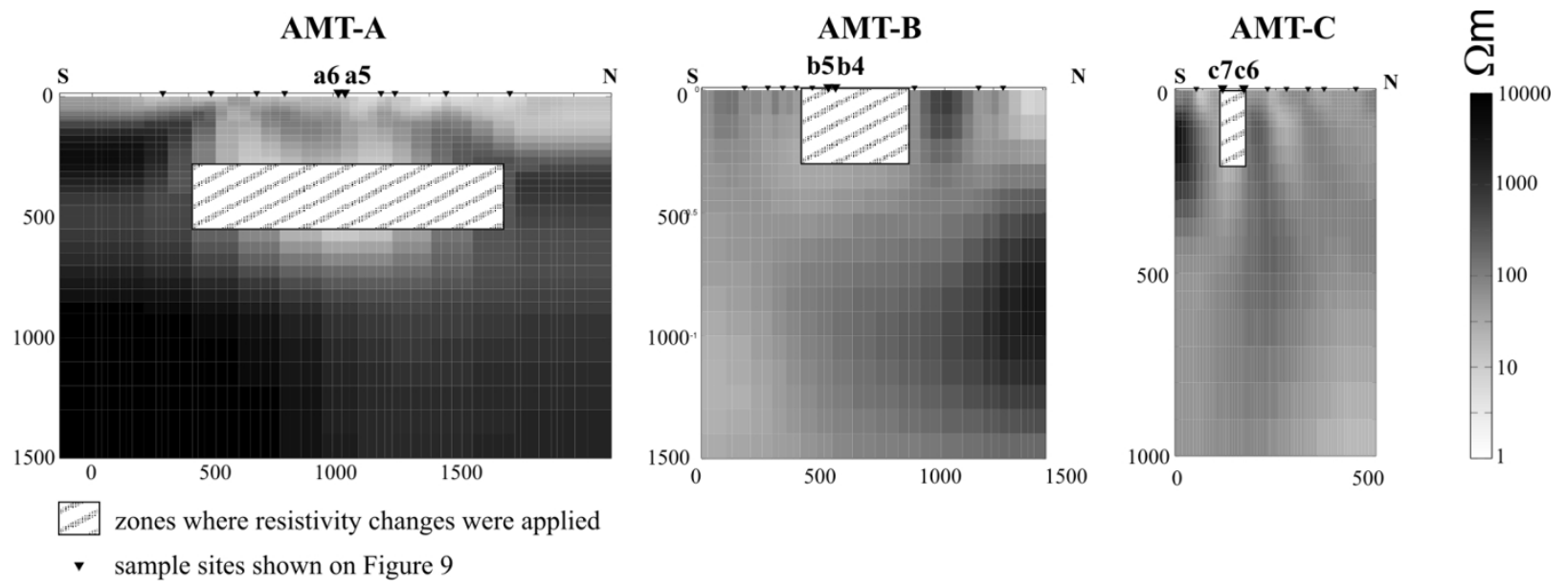

Fig. 8. Models used for testing the validity of the major conductive features on the AMT-A, AMT-B and AMT-C pro les. The highlighted zone resistivity values were replaced by 50,100 and $1000 \Omega \mathrm{m}$. Forward responses were computed to be compared with the original inversion results.

branch (IMF) of the NAF, the FZCs appear as clear features, regardless of the NAF being active or less active, which suggests a conductivity anomaly just beneath the fault traces (Figs. 7(A), 7(B) and 7(C)). These zones act as sinks for meteoric water and penetrate to deeper levels of the fault. The use of a dense distribution of sites (50 to $150 \mathrm{~m}$ ) and high frequency data (up to $10400 \mathrm{~Hz}$ ) enabled a rather high resolution over the shallow part of both fault zones.

\subsection{Validity of conductors}

The validity of conductive zones on the pro les AMTA, AMT-B and AMT-C were examined by performing sensitivity tests. In these tests, the cells that are representing the major conductive features present on the nal models were replaced by different resistivity values (50, 100 and $1000 \Omega \mathrm{m}$ ) as shown by Fig. 8. The forward responses were calculated on both the TE and TM modes and the results were compared with the original responses achieved through inversions. Figure 9 shows the apparent resistivity and phase curves for two sample sites on each pro le. For the pro les AMT-A, AMT-B and AMT-C, sites a5-a6, b4b5 and c6-c7 were chosen as sample sites, respectively. In particular, these sites were chosen because they are located over the conductive areas $\mathrm{C}_{\mathrm{A}}, \mathrm{C} 1_{\mathrm{B}}$ and $\mathrm{C}_{\mathrm{C}}$, respectively. Although there are some differences between these sites, when tting curves for different resistivity values are examined for both the TE and TM modes, it can be noticed that both modes require the corresponding conductors at different rates. For example, the requirement of the $\mathrm{C1}_{\mathrm{A}}$ is clearer on the TE mode data, when compared to the TM mode data, at sites a5 and a6. This can be explained by the length of the elongation of the conductor that is present on the pro le AMT-A, i.e. the conductor $\mathrm{C1}_{\mathrm{A}}$ is long enough to affect the TE mode data. The TM mode data is less affected, since the resistivity values on both sides of the pro le are not significantly different so as to cause charge accumulation. $\mathrm{C} 1_{\mathrm{B}}$ has an effect as far as sites b4 and b5 are concerned. This conductor is also required by both of the modes. Likewise, data on both modes demand a shallow $\mathrm{C} 1_{\mathrm{C}}$ conductor.

\subsection{Comparison between FZCs on other faults}

Both Ritter et al. (2005) and Hoffmann-Rothe et al. (2004) presented tables for comparing FZC properties of various faults. These properties include the activeness of the fault segment, and the width and depth of the FZC, as well as the lateral conductance (lateral conductance = the width of the conductor $\times$ average conductivity), observed in relation to the FZC (see the discussion in Ritter et al. (2005) on lateral conductivity; page 170).

Table 1 compares similar features, and aims to add new information on the electrical properties of the NAF and the comparison between different strike-slip faults. Our nal 2D model (Fig. 7(A)) indicates that the width and the depth values of the FZC found at the northern branch (IAF) are about $600 \mathrm{~m}$ and $750 \mathrm{~m}$, respectively. Similarly, our nal 2D model for the southern branch (IMF) (Fig. 7(B)) shows an FZC of $500 \mathrm{~m}$ width and $600 \mathrm{~m}$ depth. A smaller size FZC was observed at the eastern pro le of the IMF (AMTC) having a $150 \mathrm{~m}$ width and $300 \mathrm{~m}$ depth (Fig. 7(C)).

The sizes of respective FZCs found beneath the two branches of the NAF stand between the FCZs of the SAF at Park eld and the West Fault in Chile. The slip rates derived from GPS studies point out that the slip is partitioned with $16 \mathrm{~mm} \mathrm{yr}^{-1}$ along the IAF fault and $9 \mathrm{~mm} \mathrm{yr}^{-1}$ along the IMF fault (Straub and Kahle, 1997). Comparison between the lateral conductances of both fault segments enables us to support the idea that activity of the fault segment seems to be responsible for the increase in lateral conductance. What are the main causes for a change in the conductance at the vicinity of a fault? Some plausible answers to this question are as follows: (i) Faults tend to correspond to geological boundaries between two units with different conductivity values; (ii) fracturing caused by faulting may create pathways for brines; (iii) conductive clay-rich zones may develop near the fault zones; and (iv) an interconnected network may evolve due to the concentration of conductive materials, such as graphite or sul des, favoring electronic conduction (Jödicke et al., 1992). These possible mechanisms, in particular (ii) indicate the important role of uids.

For the AMT-A pro le, an overall two-layered structure is clear. There is a conductive sedimentary layer lying above a resistive basement rock. The thin conductive layer increases its thickness to the north. The thickness of the sedimentary layers was supposed to be about $500 \mathrm{~m}$ by 


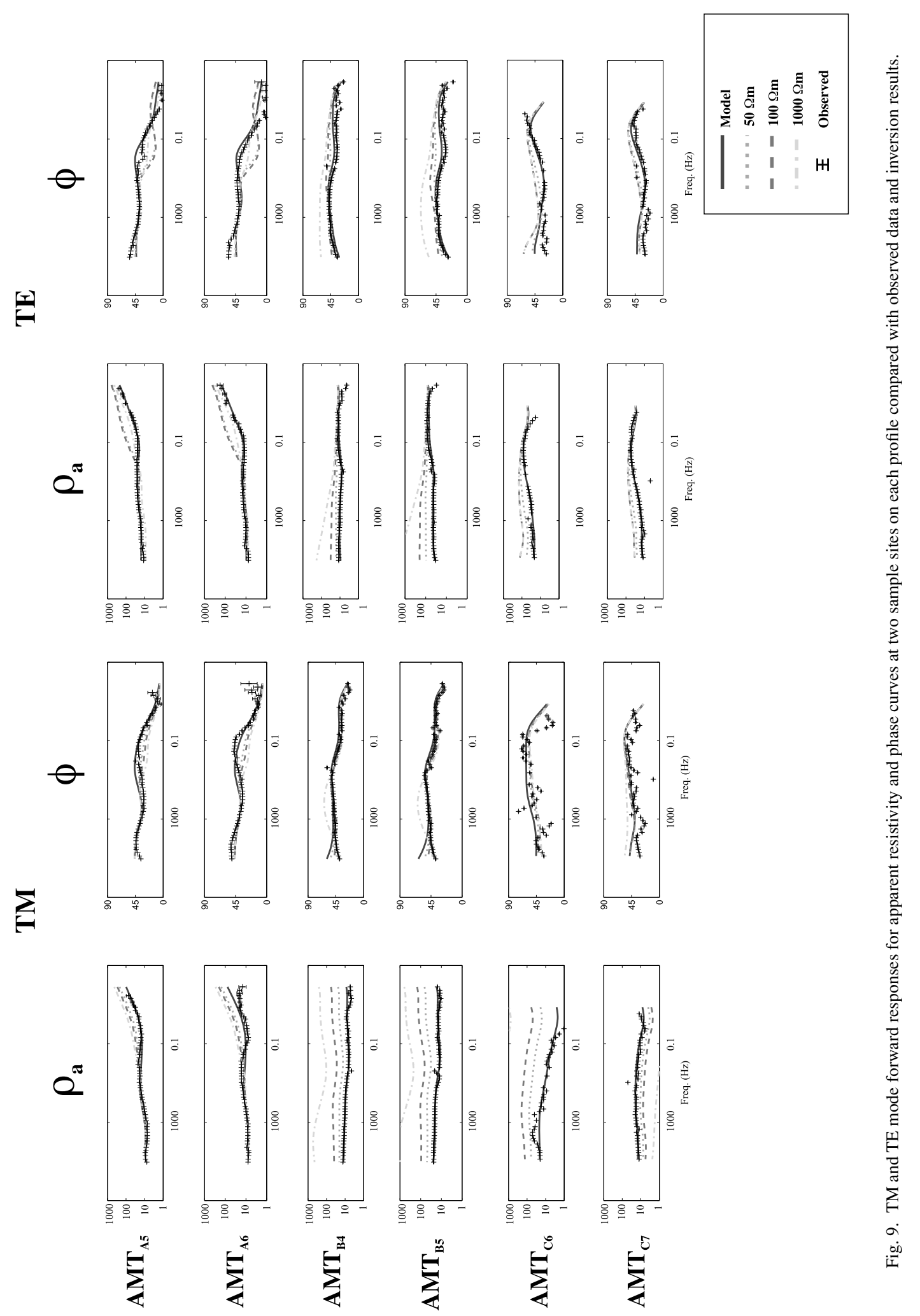


Table 1. Fault zone conductor properties for the AMT-A, AMT-B and AMT-C pro les.

\begin{tabular}{|l|c|c|c|}
\hline \multirow{2}{*}{} & \multicolumn{3}{|c|}{ North Anatolian Fault } \\
\cline { 2 - 4 } & $\begin{array}{c}\text { Izmit-Adapazar Fault } \\
\text { (northern branch) }\end{array}$ & \multicolumn{2}{|c|}{$\begin{array}{c}\text { Iznik-Mekece Fault } \\
\text { (southern branch) }\end{array}$} \\
\hline Pro le & $\mathrm{A}$ & $\mathrm{B}$ & $\mathrm{C}$ \\
FZC & $\sqrt{ }$ & $\sqrt{ }$ & $\sqrt{ }$ \\
Activity & Active $\left(M_{\mathrm{w}}: 7.4\right.$ in 1999$)$ & \multicolumn{2}{|c|}{ Less active } \\
Slip rates (GPS) & $16 \mathrm{~mm} \mathrm{yr}^{-1}$ & \multicolumn{2}{|c|}{$9 \mathrm{~mm} \mathrm{yr}^{-1}$} \\
Width of FZC & $700-800 \mathrm{~m}$ & $500 \mathrm{~m}$ & 150 \\
Depth of FZC & $750 \mathrm{~m}$ & $600 \mathrm{~m}$ & 300 \\
Lateral conductance & $\sim 750 \mathrm{~S}$ & $\sim 25 \mathrm{~S}$ & $\sim 15 \mathrm{~S}$ \\
\hline
\end{tabular}

Akartuna (1968) and Şengör et al. (2005) near the south of Izmit Bay. The thickness of the conductive layer near our pro le clearly suggests a shallower sedimentary layer, reaching to a depth of around $300 \mathrm{~m}$. Furthermore, even though the lateral resolution in our model is limited by the electrode separation of the dipoles (Hoffmann-Rothe et al., 2004), which is $70 \mathrm{~m}$ at most of our measurement sites, a Ushaped structure can be inferred beneath the IAF indicating some auxiliary faults.

The southern part of the AMT-B pro le is classi ed by sandstones, conglomerates and shale (Bargu, 1982), whereas the northern part is characterized by metamorphic formations. Such a geological border might be considered as a good example for (i) listed above, taking into account the electrical properties of sandstones, shale (conductive) and metamorphics (resistive). But the conductivity anomaly interpretation for the IMF, especially when FZC is targeted, still needs either (ii) or (iii) for a better explanation if the ionic transportation of electric charge is favored. Electronic transportation, where a conductive material such as graphite or sul de is required, is less probable along this portion of the fault.

The nal model for the AMT-C pro le bears a more complicated image and can be better interpreted with the help of the geological elucidation of Sipahioglu and Matsuda (1986). In fact, Sipahioglu and Matsuda (1986) made clear that the IMF at this location is sandwiched between two sandstone formations and continues parallel to the crashed andesite zone. Contrary to the AMT-B pro le, the crashed andesite zone appears on the north of the fault near the AMT-C pro le (Fig. 7(C)).

At this pro le $\mathrm{C} 1_{\mathrm{C}}$ and $\mathrm{C} 2_{\mathrm{C}}$ might be representing two FZCs, one being auxiliary to the other and $\mathrm{R}_{\mathrm{C}}$ is the crashed andesite zone. The most prominent feature of this pro le is the deep high conductivity anomaly $\mathrm{C}_{\mathrm{C}}$ with its southern boundary corresponding to the boundary between the crashed andesite zone and sandstones.

\section{Conclusion}

AMT data were collected along three typical pro les crossing the northern and southern branches of the North Anatolian Fault. The site separations were taken as 50 to $150 \mathrm{~m}$ in order to ensure high-resolution images of the resistivity structure. Following the dimensionality analyses, two-dimensional inversion models for both the TM and TE modes, and the TM only mode, were constructed. For all three pro les crossing two different segments of the NAF, one being active and the other being less active, the AMT data provided information on the vertical fault zone conductors (FZC) of similar sizes but different lateral conductances.

Some earlier studies performed in the area (Honkura $e t$ al., 2000; Oshiman et al., 2002; Tank et al., 2003, 2005; Kaya et al., 2009) attempted to resolve the resistivity structure at mid-crustal depths. In particular, they tried to get information about the electrical properties of the seismogenic zone. The relatively deep conductors that appeared in these studies were associated with uids that emerge as a result of metamorphic dehydration. These studies claimed that the uid rich region has an important role in earthquake generation.

Following the comparison between the three AMT prole results, a similar comparison can be made between the AMT pro le results and the earlier wideband model results (Honkura et al., 2000; Oshiman et al., 2002; Tank et al., 2003,2005 ). Although a direct comparison is not easy (this is a direct consequence of the differences in the site separations for the AMT pro les (50-100 m) and the wideband pro les $(2-3 \mathrm{~km})$ ), it is important to point out that conductors at seismogenic depths are important for understanding earthquake generation, whereas the shallow conductors (or FZCs for this particular case) are important for understanding the behavior of the fault in forming fractures that serve as pathways for brines.

Tank et al. (2005) have pointed out a deep highly conductive anomaly between the two branches (IAF and IMF) of the North Anatolian Fault. This anomaly was interpreted as a widespread partial melting zone and source for free uids at seismogenic depths. In addition to this information, the current study's results show that there are FZCs just beneath both of the fault's traces and the more active northern branch exhibits a higher lateral conductances compared to the southern branch. Although there is no distinct structural difference between the two branches in the deeper part, the current results show that there are differences in the shallow structure.

Acknowledgments. This study was supported mutually by the Ministry of Education, Science, Culture and Sports of Japan, under grant-in-aid for scienti c research no. 13373002 and Bogaziçi University, Scienti c Research Projects (BAP) no. 08HT201. This paper was improved with constructive reviews by Malcolm Ingham and an anonymous reviewer. The support of Yoshimori Honkura and Yasuo Ogawa are also acknowledged. I am grateful 
to THY (Turkish Airlines) and Ataturk Airport Customs Directorate for their kind help and support of our project.

\section{References}

Akartuna, M., Armutlu Yar madas n n Jeolojisi, Istanbul Üniv. Fen Fak. Monogr. (Tabii Ilimler k sm ), No. 20, p. 105, 1968.

Bahr, K., Interpretation of the magnetotelluric impedance tensor-regional induction and local telluric distortion, J. Geophys.-Zeitschrift Fur Geophysik, 62(2), 119-127, 1988.

Bahr, K., Geological noise in magnetotelluric data-a classi cation of distortion types, Phys. Earth Planet. Inter., 66(1-2), 24-38, 1991.

Bargu, S., The geology of Iznik-Yenişehir (Bursa)-Osmaneli (Bilecik) area, Istanbul Earth Sci. Rev., 3, 191-233, 1982

Barka, A. A., The North Anatolian Fault Zone, Anneles Tectonicae, 6, 164195, 1992.

Barka, A. A., Slip distribution along the North Anatolian fault associated with the large earthquakes of the period 1939- to 1967, Bull. Seismol. Soc. Am., 86(5), 1238-1254, 1996.

Becken, M., O. Ritter, S. K. Park, P. A. Bedrosian, U. Weckmann, and M Weber, A deep crustal uid channel into the San Andreas Fault system near Park eld, California, Geophys. J. Int., 173, 718-732, 2008.

Bedrosian, P. A., M. J. Unsworth, and G. D. Egbert, Magnetotelluric imaging of the creeping segment of the San Andreas Fault near Hollister, Geophys. Res. Lett., 29(11), 2002.

Bedrosian, P. A., M. J. Unsworth, G. D. Egbert, and C. H. Thurber, Geophysical images of the creeping segment of the San Andreas Fault: Implications for the role of crustal uids in the earthquake process, Tectonophysics, 385(1-4), 137-158, 2004.

Bibby, H. M., T. G. Caldwell, and C. Brown, Determinable and nondeterminable parameters of galvanic distortion in magnetotellurics, Geophys. J. Int., 163(3), 915-930, 2005.

Caine, J. S., J. P. Evans, and C. B. Forster, Fault zone architecture and permeability structure, Geology, 24(11), 1025-1028, 1996.

Caldwell, T. G., H. M. Bibby, and C. Brown, The magnetotelluric phase tensor, Geophys. J. Int., 158(2), 457-469, 2004.

de Groot-Hedlin, C. and S. Constable, Occam inversion to create smooth 2dimensional models from magnetotelluric data, Geophysics, 55, 16131624, 1990.

Eberhart-Phillips, D., W. Stanley, B. Rodriguez, and W. Lutter, Surface seismic and electrical methods to detect uids related to faulting, $J$. Geophys. Res., 100(B7), 12919-12936, 1995.

Electromagnetic Research Group for the Active Fault, Low electrical resistivity along an active fault, J. Geomag. Geoelectr., 34, 103-127, 1982.

Gamble, T. D., W. M. Goubau, and J. Clarke, Magnetotellurics with remote magnetic reference, Geophysics, 44, 53-68, 1979.

Groom, R. W. and R. C. Bailey, Decomposition of magnetotelluric impedance tensors in the presence of local three dimensional galvanic distortions, J. Geophys. Res., 94, 1913-1925, 1989.

Gundmundsson, A., Active fault zones and groundwater ow, Geophys. Res. Lett., 27, 2993-2996, 2000.

Gürer, A., Deep conductivity structure of the North Anatolian Fault Zone and the Istanbul and Sakarya Zones along the Gölpazar -Akçakoca prole, Northwest Anatolia, Int. Geol. Rev., 38, 727-736, 1996.

Heise, W., T. G. Caldwell, H. M. Bibby, and C. Brown, Anisotropy and phase splits in magnetotellurics, Phys. Earth Planet. Inter., 158, 107$121,2006$.

Hickman, S., R. Sibson, and R. Bruhn, Introduction to special section: Mechanical involvement of uids in faulting, J. Geophys. Res., 100, 12831-12840, 1995

Hoffmann-Rothe, A., O. Ritter., and C. Janssen, Correlation of electrical conductivity and structural damage at a major strike-slip fault in northern Chile, J. Geophys. Res., 109, B10101, 2004.

Honkura, Y., A. M. Iş kara, N. Oshiman, A. Ito, B. Üçer, S. Bar ş, M. K. Tunçer, M. Matsushima, R. Pektaş, C. Çelik, S. B. Tank, F. Takahashi, M. Nakanishi, R. Yoshimura, Y. Ikeda, and T. Komut, Preliminary results of multidisciplinary observations before, during and after the Kocaeli (Izmit) earthquake in the western part of the North Anatolian Fault Zone, Earth Planets Space, 52, 293-298, 2000.

Ikeda, Y., Geomorphological observations of the north Anatolian fault zone west of Mudurnu, in Multidisciplinary Research on Fault Activity in the Western Part of the North Anatolian Fault Zone, edited by Y. Honkura and A. M. Iş kara, pp. 6-14, 1988.

Jödicke, H., Water and graphite in the earth's crust-an approach to interpretation of conductivity models, Surv. Geophys., 13, 381-407, 1992.

Kaya, T., S. B. Tank, M. K. Tunçer, I. Rokityansky, E. Tolak, and T.
Savchenko, Asperity along the North Anatolian Fault imaged by Magnetotellurics at Düzce, Turkey, Earth Planets Space, 61(7), 871-884, 2009.

Mackie, R. L., D. W. Livelybrooks, T. R. Madden, and J. C. Larsen, A magnetotelluric investigation of the San Andreas fault at Carrizo Plain, California, Geophys. Res. Lett., 24(15), 1847-1850, 1997.

McCaig, A. M., Deep uid circulation in fault zones, Geology, 16, 867$870,1988$.

McNeice, G. W. and A. G. Jones, Multisite, multifrequency tensor decomposition of magnetotelluric data, Geophysics, 66(1), 158-173, 2001.

Mitsuhata, Y., Y. Ogawa, M. Mishina, T. Kono, T. Yokokura, and T. Uchida, Electromagnetic heterogeneity of the seismogenic region of 1962 M6.5 Northern Miyagi Earthquake, northeastern Japan, Geophys. Res. Lett., 28, 4371-4374, 2001.

Ogawa, Y. and T. Uchida, A two-dimensional magnetotelluric inversion assuming Gaussian static shift, Geophys. J. Int., 126, 69-76, 1996.

Ogawa, Y., M. Mishina, T. Goto, H. Satoh, N. Oshiman, T. Kasaya, Y. Takahashi, T. Nishitani, S. Sakanaka, M. Uyeshima, Y. Takahashi, Y. Honkura, and M. Matsushima, Magnetotelluric imaging of uids, in intraplate earthquake zones, NE Japan back arc, Geophys. Res. Lett., 28, 3741-3744, 2001.

Ogawa, Y., S. Takakura, and Y. Honkura, Resistivity structure across Itoigawa-Shizuoka tectonic line and its implications for concentrated deformation, Earth Planets Space, 54, 1115-1120, 2002.

Oshiman, N., R. Yoshimura, T. Kasaya, Y. Honkura, M. Matsushima, S. Bar ş, C. Çelik, M. K. Tunçer, and A. M. Iş kara, Deep resistivity structure around the fault associated with the 1999 Kocaeli earthquake, Turkey, in Seismotectonics in Convergent Plate Boundary, edited by Y. Fujinawa and A. Yoshida, pp. 293-303, Terra Sci. Publ. Company, 2002.

Park, S. K. and J. J. Roberts, Conductivity structure of the San Andreas fault, Park eld, revisited, Geophys. Res. Lett., 30, 2003.

Parsons, T., S. Toda, R. S. Stein, A. Barka, and J. H. Dieterich, Heightened odds of large earthquakes near Istanbul: An interaction-based probability calculation, Science, 288, 2000.

Ritter, O., T. Ryberg, U. Weckmann, A. Hoffmann-Rothe, A. Abueladas, Z. Garfunkel, and DESERT Research Group, Geophysical images of the Dead Sea Transform in Jordan reveal an impermeable barrier for uid ow, Geophys. Res. Lett., 30(14), 1741, 2003.

Ritter, O., A. Hoffmann-Rothe, P. A. Bedrosian, U. Weckmann, and V. Haak, Electrical conductivity images of active and fossil fault zones, High Strain Zones: Structure and Physical Properties, Geol. Soc. Lond. Spec. Publ., 245, 165-186, 2005.

Şengör, A. M. C., O. Tüysüz, C. Imren, M. Sak nç, H. Eyidogan, N. Görür, X. Pichon, and C. Rangin, The North Anatolian Fault: A new look, Ann. Rev. Earth Planet. Sci., 33, 37-112, 2005.

Sipahioglu, S. and T. Matsuda, Geology and Quaternary fault in the IznikMekece area, in Electric and Magnetic Research on Active Faults in the North Anatolian Fault Zone, edited by Y. Honkura and A. M. Iş kara, pp. 25-41, 1986.

Smith, J. T., Understanding telluric distortion matrices, Geophys. J. Int., 122(1), 219-226, 1995.

Straub, C. and H. G. Kahle, GPS and geologic estimates of the tectonic activity in the Marmara Sea region, NW Anatolia, J. Geophys. Res., 102, 27587-27601, 1997.

Tank, S. B., Y. Honkura, Y. Ogawa, N. Oshiman, M. K. Tunçer, M. Matsushima, C. Çelik, E. Tolak, and A. M. Iş kara, Resistivity structure in the western part of the fault rupture zone associated with the 1999 Izmit earthquake and its seismogenic implication, Earth Planets Space, 55, 437-442, 2003.

Tank, S. B., Y. Honkura, Y. Ogawa, M. Matsushima, N. Oshiman, M. K. Tunçer, C. Çelik, E. Tolak, and A. M. Iş kara, Magnetotelluric imaging of the fault rupture area of the 1999 Izmit (Turkey) earthquake, Phys. Earth Planet. Inter., 150(1-3), 213-225, 2005.

Ting, S. C. and G. W. Hohmann, Integral equation modeling of threedimensional magnetotelluric response, Geophysics, 46, 182-197, 1981.

Toksöz, M. N., A. F. Shakal, and A. J. Michael, Space time migration of earthquakes along the North Anatolian Fault and seismic gaps, Pure Appl. Geophys., 117, 1258-1270, 1979.

Tunçer, M. K., Y. Honkura, N. Oshiman, Y. Ikeda, and A. M. Is kara, Magnetic Anomalies Related to Active Folds in the North Anatolian Fault Zone, J. Geomag. Geoelectr., 43, 813-823, 1991.

Uchida, T., Smooth 2-D inversion for magnetotelluric data based on statistical criterion ABIC, J. Geomag. Geoelectr., 45, 841-858, 1993.

Unsworth, M. J., P. E. Malin, G. D. Egbert, and J. R. Booker, Internal structure of the San Andreas fault at Park eld, California, Geology, 25(4), 359-362, 1997 
Unsworth, M., G. Egbert, and J. Booker, High-resolution electromagnetic imaging of the San Andreas fault in central California, J. Geophys. Res.Solid Earth, 104(B1), 1131-1150, 1999.

Wannamaker, P. E., G. R. Jiracek, J. A. Stodt, T. G. Caldwell, V. M. Gonzales, J. D. McKnight, and A. D. Porter, Fluid generation and pathways beneath an active compressional orogen, the New Zealand Southern Alps, inferred from magnetotelluric data, J. Geophys. Res., 107(B6), 2002.

Yigitbaş, E., A. Elmas et al., Pre-Cenozoic tectono-stratigraphic compo- nents of the Western Pontides and their geological evolution, Geol. J., 34(1-2), 55-74, 1999 .

Y lmaz, Y., S. C. Genç et al., Geological evolution of the late mesozoic continental-margin of Northwestern Anatolia, Tectonophysics, 243(12), 155-171, 1995.

S. B. Tank (e-mail: bulent.tank@boun.edu.tr) 